\title{
Alexithymia and binge eating in obese outpatients who are starting a weight-loss program: A structural equation analysis
}

\author{
Chiara Conti1 | Giulia Di Francesco1 | Roberta Lanzara1,2 | Melania Severo1 | \\ Luna Fumagalli1 | Maria Teresa Guagnano3 | Piero Porcelli1 \\ 1 Department of Psychological, Health, and Territorial Sciences, University "G. d'Annunzio" of Chieti-Pescara, \\ Chieti, Italy \\ 2 Department of Dynamic and Clinical Psychology, “Sapienza” University of Rome, Rome, Italy \\ 3 Department of Medicine and Aging, University “G. d'Annunzio” Chieti-Pescara, Chieti, Italy \\ Correspondence: Chiara Conti, Department of Psychological, Health, and Territorial Sciences, University "G. \\ d'Annunzio" of Chieti-Pescara, Chieti, Italy. \\ Email: cconti@unich.it
}

Acknowledgements: None.

Conflict of Interest: The authors declare that the research was conducted in the absence of any commercial or financial relationships that could be construed as a potential conflict of interest. 


\begin{abstract}
Objective: To investigate whether obese patients with Binge Eating (BE) have higher alexithymic features; to explore the different relationships between psychological features (alexithymia, depression, and anxiety) and BE.
\end{abstract}

Method: 361 obese BE-patients were evaluated for alexithymia, psychological distress and BE. Alexithymia was measured with the 20-item Toronto Alexithymia Scale (TAS-20); BE was assessed with the Binge Eating Scale (BES), and depression and anxiety symptoms were evaluated with the Hospital Anxiety and Depression Scale (HADS).

Results: Patients with BE reported significantly higher TAS-20 total scores than those without BE $(\mathrm{p}<.001)$. The SEM analysis showed that the Difficulty in Identifying Feelings (DIF) andDifficulty in Describing Feelings(DDF) components of alexithymia affected BE along different pathways. DIF was found as a major factor influencing altered eating both directly $(\mathrm{p}=.20 *)$ and above all through the mediation of psychological distress $\left(\mathrm{p}=.19^{* * *}\right)$ while DDF affected BE only through psychological distress at a lesser extent $(\mathrm{p}=.09 * *)$.

Discussion: Alexithymic difficulties in affective awareness may play an important role in the onset and maintenance of BE, especially when patients experienced anxiety and depression symptoms. Clinicians involved in the management of obesity should address the combination of alexithymic traits and emotional distress by planning effective client-focused interventions.

Keywords: alexithymia, binge eating, obesity, anxiety, depression

\title{
Introduction
}


Obesity is a significant global cause of morbidity, mortality, and disability (Arcelus,Mitchell, Wales,\& Nielsen, 2011; World Health Organization [WHO], 2000, 2009). Overall, 40\% of the worldwide adult population is overweight and $13 \%$ obese, with rising rates (NCD Risk Factor Collaboration [NCDRisC], 2016). Several causes and risk factors for obesity andbeing overweight have been identified that are mostly related to unhealthy lifestyles, such as dietary patterns, being sedentary lifestyle, and decreases or increases in sleep duration (Mozaffarian, Hao, Rimm, Willett, \& Hu, 2011; Hruby\&Hu, 2015). Furthermore, obesity is widely recognized as one of the main causes of severe chronic and sometimes life-threatening diseases, as metabolic syndrome, cardiovascular disease, and diabetes (PiSunyer,2009). Hence, investigating behavioral factors underlying maladaptive eating behavior patterns has become of paramount importance for public health.

Eating behavior patterns are among the most investigated obesity risk factors. Increased diagnoses of clinically relevant eating disorders and subthreshold atypical eating patterns have been found to be associated with obesity, particularly binge eating (BE) behaviors (e.g. Darby et al., 2009; Makino, Tsuboi, \&Dennerstein, 2004; Pike \& Dunne, 2015). Prevalence of BE is estimated to be $4.5 \%$ in the general population and much higher in obese and overweight adults, ranging from $35 \%$ to $50 \%$ (Hudson, Hiripi, Pope,\& Kessler, 2007; Grucza, Przybeck, \&Cloninger, 2007; Dymek, Grange, \& Neven,2001), representing the most common atypical eating pattern in obese patients. BE refers to discrete eating episodes characterized by the intake of an excessive amount of food (i.e., overeating) and an associated sense of loss of control (American Psychiatric Association [APA], 2013). Episodes of BE may be suggestive of disordered eating and clinically significant, recurrent episodes of BE in the absence of compensatory behaviors (e.g., vomiting, excessive exercise) may be diagnosed with binge eating disorder (BED) (APA, 2013). BED is characterized by recurrent episodes of BE occurring, on average, at least once per week for 3 months (APA, 2013) and may be seen as a more severe form of BE. BE behaviors and BED greatly affect comorbid psychological distress and treatment outcomes of 
obesity. Overweight and obese patients who also present with BE behavior and BED symptoms tend to have poorer outcomes (e.g., Bulik, Sullivan, \&Kendler, 2002; Elfhag\&Rossner, 2005). They are more likely to report psychological disorders, including depression and anxiety disorders (Bittencourt, Lucena-Santos, \&Moraes,2012; Nicholls, Devonport, \& Blake, 2016) and have more maladaptive emotional regulation strategies (e.g., Gianini, White, \&Masheb, 2013). These patients are more likely to drop out of weight loss treatment (Goode et al., 2016) and are faster to regain weight after weight loss interventions (Marcus, Wing, \& Hopkins, 1988;Pagoto et al., 2007). Since the effects of various treatment strategies for reducing obesity are far from definite, many underlying psychological traits of eating behavior have been studied, highlighting a central role played by maladaptive coping strategies, difficulties in impulse control, and deficiencies in adaptive affect regulation (for a review, see Davin\& Taylor 2009). Alexithymia is an overarching personality dimension of broadly defined disorders affecting the emotional regulation, which is thought to be involved in the clinical manifestation and the maintenance of both obesity and BE. Alexithymia is currently conceived as composed by two higher order factors including a deficit of affect awareness (as difficulty identifying feelings, DIF, and difficulty describing feelings, DDF) and operatory thinking (externally-oriented thinking, EOT, and poor imaginal processes) (Luminet, Bagby, \& Taylor, 2018).Current evidence shows that the alexithymic deficit is likely to affect health in different ways. Alexithymia has been consistently evidenced to associate with affective states (e.g., depressive symptoms), maladaptive behaviors (e.g., altered eating behavior), psychopathology directly related to emotional dysregulation (through somatosensory amplification leading to low tolerance to painful stimuli such as chronic pain syndromes), posttraumatic shutdown of emotions (e.g., acute reactions to illness), and altered autonomic, endocrine and immune activity leading to tissue damage (e.g., vulnerability to inflammatory processes) (for a review, see Luminet et al., 2018). It has been hypothesized that the alexithymic deficit in the cognitive processing of emotions leads to an 
amplification of the somatic sensations. These somatic sensations coexist with emotional arousal because of the affect dysregulation caused by emotional hyperactivation and reduced awareness of selfstates(Honkalampi, De Berardis, Vellante, \&Viinamäki, 2018, p. 142). This could explain the tendency to regulate tension through compulsive behaviors suchassubstance abuse and BE (Taylor \&Bagby, 2013). Previous investigations have indeed identified a link between alexithymic traits and chronic medical conditions (Porcelli,De Carne, \& Leandro,2014) and mental illnesses (van der Velde et al., 2015), including affective disorders (Bankier,Aigner, \&Bach, 2001; Honkalampi,Hintikka, Laukkanen, Lehtonen, \&Viinama ki,2001; Saarijärvi, Salminen, \&Toikka, 2001; Leweke,Leichsenring, Kruse, \& Hermes, 2012), somatoform disorders (Karvonen et al., 2005; Burba et al., 2006), and eating disorders (Nowakowski,McFarlane,\& Cassin, 2013; Westwood, Kerr-Gaffney, Stahl, \&Tchanturia, 2017). In a recent meta-analysis (Westwood et al., 2017), alexithymia showed a close association with both anorexia and bulimia nervosa) with large effect sizes ( $d=1.44$ and 1.26 , respectively). This metaanalysis identified only five studies on alexithymia in individuals with BED suggesting a stronger involvement of the dimensions in the affect unawareness higher-order factor (DIF and DDF) over the operatory thinking factor (EOT).

In obesity research, alexithymia is reported to be significantly more frequent among obese patients compared to controls without obesity (Da Ros,Vinai, Gentile, Forza, \&Cardetti, 2011; Fernandes, Ferreira-Santos, Miller,\& Torres, 2017; Kirsten, \&Ridout, 2018, p. 158). In a recent cross-sectional study, alexithymia, particularly the DIF factor, was associated with abdominal obesity in patients with type 1 diabetes (Melin et al., 2017) and predicted failure of a cognitive behavioral therapy group intervention for overweight and obese patients (Sawamoto et al., 2016).

A higher level of alexithymia was also found in obese patients with BED compared to healthy subjects and obese patients without BED (Pinaquy, Chabrol, Simon, Louvet, \&Barbe, 2003; Aloi,Rania, Caroleo, De Fazio, \& Segura-García, 2017).However, to our knowledge, while previous studies limited 
to between-group comparisons, only one study (Aloi et al., 2017) analyzed how much alexithymia could independently predict BED in obese patients after controlling for co-variables and no study has investigated so far the predictive role of each alexithymic factors in this population. Furthermore, alexithymic BED patients also showed higher psychological distress, particularly anxiety and depressionsymptoms (Conti et al., 2017; Carano et al., 2006; Wheeler, Greiner, \&Boulton,2005).

However, evidence at this regard is not unequivocal and controversial findings have been shown. Some accounts suggest a conceptual overlap between alexithymia and psychological distress (e.g., Li, Zhang, Guo, \& Zhang, 2015) while others claim they are two distinct constructs (for a review, see Honkalampi, De Berardis, Vellante, \&Viinamäki, 2018, p. 142).

To our knowledge, to date, no study has investigated the pathways through which alexithymia and psychological distress may influence BE in obese patients. The aim of this studyis therefore comprised of two objectives: 1) to investigate whether obese patients with BE had higher alexithymictraits than those without BE, and 2) to explore the different relationship between psychological features (alexithymia, depression, and anxiety) and BE.

The expectation was (1) patients with BE would exhibit more alexithymic, depression, and anxiety manifestations than non-BE obese patients; and (2) the alexithymiccomponents related to lack of affective awareness (DIF and DDF) would affect BE through the mediating role of depression and anxiety symptoms rather than directly.

\section{Materials and Methods}

\section{Participants}

A consecutive and unselected sample of 427 newly referred patients to the Obesity Centre at the University Clinical Hospital of Chieti (Italy) wasrecruited during the first medical examination. 
Patients were firstly screened for medical workup and motivation to the dietary program which is characterized by an integrated multicomponent approach to weight control including daily food intake, paced eating, adoption of a healthy lifestyle, behavioral modification of risk factors related to eating behavior, and psychological counseling aimed to address individual and interpersonal distress. Of the 427 recruited patients, $361(84.5 \%)$ accepted to be enrolled. The main reason for not participating was lack of time. To optimize ecological validity, all adult outpatients aging from 18 to 70 years old and with Body Mass Index $(\mathrm{BMI}) \geq 30$ were included. Self-reported psychiatric disorders or use of psychoactive substances in the past 10 years, cognitive impairment, pregnancy, inability to perform or understand the self-rating scales, documented or self-reported thyroid dysfunction, diabetes, chronic liver disease, renal failure, and any other physical diseases which could interfere with eating behavior were considered exclusion criteria.

All patients provided written informed consent to participate in the study. The study was approved by the local Ethics Committee and carried out in accordance with the World Medical Association Declaration of Helsinki and its subsequent revisions (WMA, 2014).

\section{Measures}

\section{Socio-demographic and clinical characteristics}

The socio-demographic and clinical factors such as age, gender, BMI, education level, marital status, and the onset of obesity were collected through an ad-hoc semistructured interview. BMI $\geq 30$ was used as the cut-off for determining obesityand was calculated as the ratio of weight in kilograms to square of height in meters $\left(\mathrm{kg} / \mathrm{m}^{2}\right)$.

\section{Depression and anxiety symptoms}

The Hospital Anxiety and Depression Scale (HADS) (Zigmond\&Snaith, 1983; Bjelland,Dahl, Haug,\&Neckelmann, 2002) was used to assess depression and anxiety symptoms. The HADS is a 14- 
item self-report scale that is widely used to evaluate psychological distress in patients with physical health problems and includes two separate 7-item subscales for depression (HADS-D) and anxiety (HADS-A) scored on a 4-point Likert scale ranging from 0 (no symptom) to 3 (definite experience of symptoms). To each subscale, scores ranging between 8 to10 are considered borderline and $>11$ severe symptoms of anxiety and depression. The HADS has been widely used in various medical settings, demonstrating good reliability and validity (Norton,Cosco, Doyle, Done,\& Sacker, 2013). For this sample, Cronbach's $\alpha$ for HADS-D was 0.78 and for HADS-A 0.81 .

\section{Alexithymia}

Alexithymia was assessed using the self-report 20-item Toronto Alexithymia Scale (TAS-20) (Bagby,Parker, \& Taylor, 1994). Responses are scored on a 5-point Likert scale, from $1=$ strongly disagree to $5=$ strongly agree, with total scores ranging from 20 to 100 . The TAS-20 has a three-factor structureand produces three subscale scores. The DIF subscale, consisting of seven items, assesses the ability to identify feelings and distinguish them from bodily sensations that accompany emotions. The DDF subscale, consisting of five items, assesses the ability to describe feelings to other people. The EOT subscale, consisting of eight items, assesses the tendency of individuals to focus their attention externally over internal events. The threshold for higher levels of alexithymia is considered a score of 61 or higher (Taylor,Bagby, \& Parker, 1997). The scale represents the standard measure for alexithymia because of its psychometric properties ofinternal consistency, construct validity, and factor structure that have been shown worldwide (Parker,Taylor,\&Bagby, 2003; Taylor,Bagby, \& Parker, 2003; Bressi et al., 1996). For this sample, Cronbach's $\alpha$ was 0.84 for the total scale, 0.86 for the DIF, 0.70 for the DDF, and 0.65 for the EOT subscales.

\section{Binge Eating}


The severity of BE behavior was measured using the Binge Eating Scale (BES) (Gormally, Black,Daston, \&Rardin, 1982). The BES is a 16-item self-report questionnaire that yields a total score ranging from 0 to 46 . Scores of $\geq 27$ have conventionally served as a cut-off value for identifying the presence of severe BE, $\geq 18$ for moderate BE, and $\leq 17$ for minimal or no BE (Greeno,Marcus, \& Wing, 1995). For this sample, Cronbach's $\alpha$ was 0.89.

\section{Statistical analysis}

A 3-step strategy was used for data analysis.

First, socio-demographic, and clinical variables between outpatients with and without BE were compared using Student's $t$-tests or $\chi^{2}$, and effect sizes were expressed as standardized mean differences. A standardized effect size (Cohen's d) of $0.20-0.50$ is considered small, $0.50-0.80$ moderate, and >0.80 large. The reliability of the applied scales was assessed using Cronbach's $\alpha$ coefficient.

Second, binary logistic regression analysis was performed to identify major determinants that best predict $\mathrm{BE}$. BE was considered as a dependent variable (dummy coded: $0=$ without $\mathrm{BE}$; $1=$ with $\mathrm{BE}$ ) and the independent variables were age, gender, education, marital status, BMI, depression, and anxiety symptoms and alexithymia. Four regression models were processed and regression coefficients, the related confidence intervals, odds ratio, and $p$ values were estimated.In the first model, the 4 sociodemographic variables describing the characteristics of participants were forced in, whereas in the 3 following models the further factors potentially explaining the outcome were entered. In particular, we aimed to investigate the extent to which each factor (e.g., BMI in the second model, psychological distress in the third model, and alexithymia in the fourth model) were able to significantly add to the final explained variance of BE. 
Third, Structural Equation Model (SEM) was used to assess the effect of each latent dimension of alexithymia (i.e. DIF, DDF, and EOT) on the severity of BE through the mediating role of depression and anxiety symptoms. In particular, our model included three exogenous latent traits (DIF, DDF, and EOT), one endogenous latent factor for the BE (with the items as measurement loading) and two continuous mediator variables. SEM is a set of statistical techniques used to measure and analyze the relationships of observed and latent variables. It examines linear causal relationships among variables, while simultaneously accounting for measurement error. SEM can be viewed as a combination of factor analysis and regression or Path Analysis. Latent factors represent the related theoretical constructs that can be considered latent traits or "true" variables underlying the measured items. The theoretical constructs in this study were alexithymia and BE, with theirrelated TAS-20 and BES scores as latent traits. The measurement model can be of interest, but the focus of the investigation is usually set on the relationships among factors or between factors and observed variables (the structural part of the model) (Bollen, 1989, 2002; Browne \&Cudeck, 1993).

Missing data were replaced by way of multiple imputation algorithms. SEM, with a maximum likelihood estimation method, was used to evaluate the fit of the hypothesized model based on the following multiple criteria: $c h i$-squared $\left(\chi^{2}\right)(p$ value >.05), Root Mean Square Error of Approximation (RMSEA) close to 0.06 or less for a well fitted model, Comparative Fit Index (CFI) near 0.90 or greater and Tucker-Lewis Index (TLI) near 0.90 or greater (Schumacker\&Lomax, 1996). Hypotheses regarding the structural relationships among the constructs in the final model were evaluated using the magnitude of path coefficients (standardized coefficient) and their significance (Bentler, 1990).

\section{Results}

\section{Characteristics of the sample}


Table 1 reports the comparisons between patients with and without BE.

The 361 participants reported a mean age of $45.74 \pm 14.24$ years and as expected in obesity (Kanter\& Caballero, 2012; Garawi,Devries,Thorogood, \&Uauy, 2014), were predominantly women (n=254, 70.4\%). Most of the participants had graduated from high or secondary school $(\mathrm{n}=169,48.7 \%$, and $\mathrm{n}=99,28.5 \%$, respectively) and married $(\mathrm{n}=254,73.2 \%)$. Based on BES thresholds (see Methods), onethird of obese patients showed a clinically significant BE pattern (n=124, 34.3\%). Apart from the expected higher prevalence of women in the $\mathrm{BE}(\mathrm{n}=100,80.6 \%)$ than non-BE group $(\mathrm{n}=154,65 \%)$ $\left(\chi^{2}=3.12, p<.001, d=0.34\right)$, no sociodemographic and weight-related differences were found between the group.

Between subgroups comparison

The two subgroups of patients with and without BE were remarkably different when they were evaluated for alexithymia and psychological distress, with high effect sizes in the moderate rage.Patients with $\mathrm{BE}$ reported significantly higher TAS-20 total scores than those without BE (55.20 $\pm 12.45 v s .46 .09 \pm 13.25$, respectively; $\mathrm{t}=6.31, \mathrm{p}<.001, \mathrm{~d}=0.68)$. Significant similar group differences were found for the DIF and DDF but not the EOTcomponents of the alexithymia construct. By using the traditional TAS-20 cut-off level, patients in thehigher range of alexithymia were significantly more prevalent in the $\mathrm{BE}(\mathrm{n}=51,41.1 \%)$ than the non-BE group $(\mathrm{n}=40,16.9 \%)\left(\chi^{2}=5.22\right.$, $\mathrm{p}<0.01, \mathrm{~d}=.70$ ). Moreover, patients with BE showed significantly higher depression (HADS- 
$\mathrm{D}=9.65 \pm 4.20)$ and anxiety $(\mathrm{HADS}-\mathrm{A}=9.50 \pm 3.75)$ scores than those without $\mathrm{BE}(5.87 \pm 3.92$ and $6.57 \pm 4.00$, respectively) ( $d=0.80$ and $d=0.74$, respectively).

Predicting BE from alexithymia, anxiety, and depression

Table 2 shows four regression models with BES score as a binary outcome criterion. In the firstmodel, sociodemographic characteristics (age, gender, education, and marital status) explained $2 \%$ of BE, with only female gender showing the greater OR of $2.15(95 \% \mathrm{CI}=1.25-3.75)$. Adding BMI produced a very small and not significant added predictor of $\mathrm{BE}$ of $1 \%$ (Model 2). When anxiety $(\mathrm{OR}=1.10,95 \%$ C.I. $=1.02-1.18)$ and depression $(\mathrm{OR}=1.20,95 \%$ C.I. $=1.11-1.29)$ were added in Model 3, they significantly explained an added $17 \%$ of BE variance, that was increased by $2 \%$ when the TAS-20 was included as predictor in Model $4(\mathrm{OR}=1.03,95 \% \mathrm{CI}=1.01-1.29)$.

\section{Structural equation model}

In support of the binary logistic regression analysis, SEM analyses were performed to test the direct, indirect, and total effects in a mediation model of each latent dimension of alexithymia (i.e. DIF, DDF, and EOT) on BE mediated by depression and anxiety symptoms. The structural components of the model included three exogenous latent traits (DIF, DDF, and EOT), one endogenous latent factor for the $\mathrm{BE}$, and two continuous mediator variables. Figure 1 shows the path analysis and parameter estimates. All the observed variables were loaded on their corresponding latent constructs, supporting the validity of the construct of each latent construct, and standardized residuals were normally distributed. 
The parameter model estimates indicated that DIF exerted a significant direct positive effect on BE $(\beta$ $=.20)$ whereasthere were no significant direct effects of DDF and EOT dimensions $(\beta=.02, \beta=-.02$, respectively). In addition, a significant direct effect of depression and anxiety symptoms $(\beta=.27, \beta=$ .19 , respectively) was found on BE. In other words, the higher the alexithymic difficulty in identifying feelings and psychological distress, the greater the increase of BE behaviors.

The significant indirect and total effects are shown in Table 3.

SEM showed a positive and indirect effect of DIF on BE through the mediation of depression and anxiety symptoms $\left(\beta_{\text {indirect }}=.19, \mathrm{p}<.001\right)$. DDF significantly influenced BE $\left(\beta_{\text {indirect }}=.09, \mathrm{p}<.01\right)$ exclusively through the mediation role of depression and anxiety symptoms. There was no significant indirect effect of the EOT dimension $\left(\beta_{\text {indirec }}=.06, \mathrm{p}=.77\right)$ on BE. Finally, the total effect of DIF on BE was significant $(\beta=.39, \mathrm{p}<.01)$ but there were no significant total effects of DDF and EOT constructs on BE.

The values of multiple fit indices indicated that the proposed model provided good fit data, $\chi^{2}=$ 898.045, $\mathrm{df}=368, \mathrm{p}=.000, \mathrm{TLI}=.90, \mathrm{CFI}=0.90, \mathrm{CD}=.98$ and $\mathrm{RMSEA}=.053$.

In sum, the SEM analysis showed that the DIF and DDF components of alexithymia affected BE along different pathways.DIF was found as being a major factor influencing altered eating both directly and notably through the mediation of psychological distress.DDF affected BE only through psychological distress at a lesser extent.

\section{Discussion}

All the obese patients recruited in this studywere self-referred to a clinical serviceto follow a dietary regimen in order to lose weight. Therefore, they can be consideredas actively motivated persons engaging in a multicomponent program that includes controlled nutritional balance, daily food intake, paced eating patterns, behavioral modifications, and psychological counseling. Furthermore, the 
development of BE patterns may be seen as a behavioral factor stemming from distressing emotional states (as confirmed by scoring high on the psychological scales of anxiety and depression) and the joint difficulty in the cognitive processing of those emotional states (as confirmed by the higher prevalence of alexithymia in patients with $\mathrm{BE}$ ). Although motivated to undergoing an integrated intervention for weight control, obese subjects presenting with a major component of $\mathrm{BE}$ are nonetheless more likely to obtain negative intervention outcomes as failure of weight control and unhealthy eating behaviors, dropping out prematurely from the intervention program, and faster regaining weight after the end of the intervention period (for references, see the Introduction).Investigating the role played by psychological distress and alexithymic traits may, therefore, shed a light on the personality profile of obese subjects, who are likely to fail the dietary modification program, notwithstanding their initial motivation.

Both our hypothesis were confirmed. As expected in our first hypothesis, obese patients frequently engaged in BE behavioral patterns were more psychologically distressed and had more alexithymic deficiencies than those without BE, even though they share a similar motivation to change their dietary habits. In our second hypothesis, the twocomponents of the alexithymia construct (DIF and DDF) were expected to play a major role in explaining the distressing and compulsory BE behavior.This hypothesis was confirmed by our finding thatdifficulty identifying and communicating feelings were linked to BE both directly (DIF) and through the relevant contribution of anxiety and depression as mediating factors (DIF and DDF).

In our first hypothesis, obese patients with BE were expected toexhibit more anxious, depression and alexithymictraits than non-BE patients. Consistently, we found that alexithymia, as well asdepression and anxiety symptoms, independently predicted the severity of BE in obese patients by explaining $19 \%$ of its variance. A wide body of literature showed evidence of a robust association of alexithymia with BE episodes (Carano et al., 2012; Pinna et al., 2011; Wheeler et al., 2005)and emotional eating (i.e., 
overeating in response to negative affect) (Pinaquy et al., 2003)in obese patients with BED. As suggested, individuals with higher alexithymic characteristics are likely to abuseexternal regulators as alcohol, substances, and food for regulating emotional arousal (Pinaquy, 2003; Mattila, 2008;Harrison, Sullivan, Tchanturia, \& Treasure, 2010; Svaldi, Griepenstroh, Tuschen-Caffier, \&Ehring, 2012),being unable to cognitively process their emotions adaptively (Speranza et al, 2005).

Also, as expectedin our first hypothesis, anxiety, and depression symptoms had a predictive role on BE. According to a currently prevalent theoretical model, disordered eating behaviors are often undertaken as an attempt to regulate or avoid negative affects (Heatherton \&Baumeister, 1991; Stice et al., 2001). For example, Hilbert,\&Tuschen-Caffier(2007) found that mood was significantly more negative prior to BE episodes when compared with normal eating episodes among participants diagnosed with BED whilethis pattern did not occur in healthy controls. Moreover, a high degree of comorbidity between BED and mood and anxiety disorders (Hudson et al., 2007), high levels of depression(Wheeler et al., 2005) and anxiety (Bydlowsky et al., 2005) symptomsin BED patients have been reported. The predictive role of anxiety and depression symptoms on BE in obese patients was also reported by studies largely focused on negative emotions as antecedents of BE. Negative mood, sadness, tension, and instability of emotions were found to be antecedents of BE in adult BED-obese patients (Nicholls et al., 2016). In our second hypothesis, alexithymia was expected to be linked to BE more likely through the mediating role played by psychological distress. We found that while DIF was associated with BE both directly and indirectly through anxiety and depression, DDF significantly predicted BE only through the mediation of depression and anxiety symptoms. No significant effect of EOT on BE has been found. These results suggest that the impact of alexithymia on BE may occur at both a molar and molecular levels according to which facets of the construct are involved. From one side, alexithymia as the whole phenomenon is associated to BE. From the other side, distinct roles are played by the different facets of 
the construct. The DIF factor (i.e., difficulty being aware of one's own feelings) is directly linked to BE while the effect of DIF is mediated by psychological distress when also the DDF factor (i.e., difficulty describing one's own feelings to others) is considered.

Some authors argue that alexithymia may play an indirect role in disordered eating only through the mediation of anxiety (Eizaguirre, de Cabezon, de Alda,Olariaga, \&Juaniz2004) and depression (Torres et al., 2015). Some others suggested that alexithymia has to be considered only as a state-dependent phenomenon triggered by high psychological distress rather than a stable and enduring personality trait (Elfhag\&Lundh, 2007). Finally, other studies pointed-out alexithymia as a stable personality trait and independent of psychological distress. For example, Honkalampi et al. (2017) observed that alexithymia with or without concurrent depression symptoms may involve some unhealthy pattern in eating behavior given the positive association between alexithymia and eatingdisorder, even after controlling for depression (e.g. Courty, Godart, Lalanne, \&Berthoz., 2015; Franzoni et al., 2013; Wheeler et al., 2005). In sum, the evidence supports a directas well as an indirect role of alexithymia in the expression of symptoms in patients with an eating disorder.

Previous findings suggest that the different components of alexithymia should be considered separately because the global TAS-20 score might have a ceiling effect, thus hiding the different weights of the internal facets of the construct (Swift,Stephenson, \& Royce,2006). Indeed, our findings are consistent with the literature suggesting a greater roleof difficulties in affect awareness (i.e. DIF and DDF) than operatory thinking (i.e. EOT) in eating disorders(Nowakoski, 2013; Westwood, 2017) and obesity (Pinna et al., 2011; Melin et al., 2017). A possible explanation would be that EOT showed poor internal consistency in some studies (e.g. Loas et al., 2001; Torres et al., 2015; Amianto,Bertorello, Migliore, Abbate-Daga, \&Fassino, 2016), including our study. Nevertheless, another tentative explanation would be that lack of insight and emotional awareness might play a major role in emotion regulation deficits as a core feature of BE. In our findings, DIF was associated with BE, regardless of the mediation of 
depression and anxiety symptoms. Larsen,van Strien, Eisinga, \& Engels(2006) found that, after controlling for depression, DIF scores predicted emotional eating in obese participants and Ouwns, Van Strien,\& Van Leeuwe (2009) replicated this relationship in a sample of weight-concerned women. This possible primacy of DIF in predicting overeating has recently been supported by results from experimental studies. They have shown that DIF may foster the tendency to misinterpret the visceral sensations related to hunger and satiety, thus leading to maladaptive eating patterns (Nakao,Barsky,Kumano, \&Kuboki, 2002; Kano,Hamaguchi, Itoh, Yanai, \&Fukudo, 2007; Herbert, Herbert, \&Pollatos,2011; Ernst et al., 2014; Scarpazza, Làdavas, \& di Pellegrino, 2015; Jenkinson, Taylor, \& Laws, 2018). Recent neuroscientific findings suggest that obesity may be associated with hypersensitivity to interoceptive signals of hunger and insensitivity to interoceptive signals of satiety (Simmons \&DeVille, 2017). Awareness of signals of somatic arousal may not help to control emotional responses but also contribute meaningfully to understand how somatic sensations are experienced as emotions. The inability to recognize and be aware of feelings leads to difficulties expressing and communicating emotional and mental states. Consequently, DDF alone has no direct effect on BE, but it becomes significantly influential BE when mediated by additional psychological distress symptoms. Indeed, the presence of high levels of DIF is associated with a less favorable prognosis and poorer treatment responses of the long-term outcome of patients with BE (Speranza,Loas, Wallier, $\&$ Corcos,2007) and obesity (Sawamoto et al., 2016).

Several limitations are to be acknowledged. First, a consecutive non-probabilistic sample was used in this study. Future studies with probabilistic sampling procedures will be useful to investigate the involvement of alexithymia in BE. Second, the cross-sectional nature of our study does not allow us to determine the predictive impact of DIF on the development and maintenance of BE symptomatology over time, given that only a longitudinal design could help to clarify this point. Third, the use of selfreport measures for alexithymia and $\mathrm{BE}$ were not compared within a multimethod assessment 
procedure as structured interviews. Our next step in investigating the relationships between alexithymia, psychological distress and BE in obesity is therefore to obtain clinically relevant information on patients from multiple sources.

With these limitations in mind, obese patients who exhibit BE behavioral patterns should be screened for their level of psychological distress and, particularly, alexithymic traits because the difficulty in awareness, expression, and communication of feelings are likely to influence the clinical presentation. Even though obese patients in our setting, as well as other similar settings, are basically motivated to start a weight loss program, clinicians are strongly encouraged to assess altered eating behaviors, psychological distress, and alexithymia.

The present study has found that alexithymicdifficulties in affective awareness may play an important role in the onset and maintenance of BE, particularly in the presence of factorslike anxiety and depression symptoms. Psychological interventions have been shown to be highly effective in reducing anxiety and depression (Cuijpers, Cristea, Karyotaki, Reijnders, \&Huibers,2017). Alexithymia can be also successfully reduced with therapeutic interventions and findings from treatment studies of alexithymia are highly encouraging (Ogrodniczuk, Kealy, Hadjipavlou, \& Cameron,2018). Tailored interventions on specific characteristics of overweight and obese patients as the presence of BE, distress, and deficits in the cognitive processing of emotions should be carefully evaluated by clinicians to enhance the therapeutic effectiveness of weight control programs.

\section{References}


Aloi, M., Rania, M., Caroleo, M., De Fazio, P., \&Segura-García, C. (2017). Social Cognition and Emotional Functioning in Patients with Binge Eating Disorder. European Eating Disorders Review, 25(3), 172-178. doi:10.1002/erv.2504

American Psychiatric Association (2013). Diagnostic and Statistical Manual of Mental Disorders, 5th Edn. Arlington, TX: American PsychiatricAssociation.doi:10.1176/appi.books.9780890425596

Amianto, F., Bertorello, A., Migliore, F., Abbate-Daga, G., \& Fassino, S. (2016). Alexithymia in anorexia and bulimia: Ubiquitous and primary trait?. Cogent Psychology, 3(1), 1185994. doi: $10.1080 / 23311908.2016 .1185994$

Arcelus, J., Mitchell, A. J., Wales, J., \& Nielsen, S. (2011). Mortality rates in patients with anorexia nervosa and other eating disorders. A meta-analysis of 36 studies. Archives of General Psychiatry, 68(7), 724-731. doi:10.1001/archgenpsychiatry.2011.74

Bagby, R. M., Parker, J. D., \& Taylor, G. J. (1994). The twenty-item Toronto Alexithymia Scale-I. Item selection and cross-validation of the factor structure. Journal of psychosomatic research, 38(1), 23-32. doi:10.1016/0022-3999(94)90005-1

Bankier, B., Aigner, M., \& Bach M. (2001). Alexithymia in DSM-IV disorder: comparative evaluation of somatoform disorder, panic disorder, obsessive-compulsive disorder, and depression.

Psychosomatics, 42, 235-40. doi:10.1176/appi.psy.42.3.235

Bentler, P. M. (1990). Comparative fit indexes in structural models. Psychological Bulletin, 107, 238246. doi: $10.1037 / 0033-2909.107 .2 .238$

Bittencourt, S. A., Lucena-Santos, P., Moraes, J. F. D., \& Oliveira, M.D.S. (2012). Anxiety and depression symptoms in women with and without binge eating disorder enrolled in weight loss 
programs. Trends in psychiatry and psychotherapy, 34(2), 87-92. doi:10.1590/S223760892012000200007

Bjelland, I., Dahl, A.A., Haug, T.T. \&Neckelmann, D. (2002). The Validity of Hospital Anxiety and Depression Scale. An Updated Literature Review. Journal of Psychosomatic Research. 52(2): 69 - 77. doi:10.1016/S0022-3999(01)00296-3

Bollen, K. A. (1989). Structural Equations with Latent Variables. New York, NY: Wiley Inter Science Publication.

Bollen, K. A. (2002). Latent variables in psychology and social sciences. Annual review of psychology, 53, 605-634. doi:10.1146/annurev.psych.53.100901.135239

Bressi, C., Taylor, G.J., Parker, J.D.A., Bressi, S., Brambilla, V., Aguglia, E., ... Invernizzi, G. (1996). Cross-validation of the factor structure of the 20-item Toronto Alexithymia Scale: An Italian multicenter study. Journal of psychosomatic research, 41:551-9. doi:10.1016/S0022-3999(96)00228-0

Browne, M. W., \&Cudeck, R. (1993). "Alternative ways of assessing model fit," in Testing Structural Equation Models, ed. K. A. Bollen and J. S. Long. Newbury Park, CA: SAGE, pp 136-162. doi: $10.1177 / 0049124192021002005$

Bulik, C. M., Sullivan, P. F., \&Kendler, K. S. (2002). Medical and psychiatric morbidity in obese women with and without binge eating. International Journal of Eating Disorders, 32(1), 72-78. doi:10.1002/eat.10072

Burba. B., Oswald. R., Grigaliunien. V., Neverauskiene. S., Jankuviene. O., \&Chue. P. (2006) A controlled study of alexithymia in adolescent patients with persistent somatoform pain disorder. The Canadian Journal of Psychiatry, 51:468-471. doi:10.1177/070674370605100709 
Bydlowski, S., Corcos, M., Jeammet, P., Paterniti, S., Berthoz, S., Laurier, C., ...Consoli, S. M. (2005). Emotion-processing deficits in eating disorders. International Journal of Eating Disorders, 37(4), 321329. doi: $10.1002 /$ eat.20132

Carano, A., De Berardis, D., Campanella, D., Serroni, N., Ferri, F., Di Iorio, G. ... Di Giannantonio, M. (2012). Alexithymia and suicide ideation in a sample of patients with binge eating disorder. Journal of PsychiatricPractice, 18(1), 5-11. doi: 10.1097/01.pra.0000410982.08229.99

Carano, A., De Berardis, D., Gambi, F., Di Paolo, C., Campanella, D., Pelusi, L., ... Cotellessa, C. (2006). Alexithymia and body image in adult outpatients with binge eating disorder. International Journal of Eating Disorders, 39(4), 332-340. doi:10.1002/eat.20238

Conti, C., Lanzara, R., Scipioni, M., Iasenza, M., Guagnano, M. T., \&Fulcheri, M. (2017). The relationship between binge eating disorder and suicidality: a systematic review. Frontiers in psychology, 8, 2125. doi: 10.3389/fpsyg.2017.02125

Courty, A., Godart, N., Lalanne, C., \&Berthoz, S. (2015). Alexithymia, a compounding factor for eating and social avoidance symptoms in anorexia nervosa. Comprehensive Psychiatry, 56, 217-228. doi: 10.1016/j.comppsych.2014.09.011.

Cuijpers, P., Cristea, I.A., Karyotaki, E., Reijnders, M., \&Huibers, M.J. (2017). How effective are cognitive behavior therapies for major depression and anxiety disorders? A meta-analytic update of the evidence. World Psychiatry, 15, 245-258. doi: 10.1002/wps.20346

Da Ros, A., Vinai, P., Gentile, N., Forza, G., \&Cardetti, S. (2011). Evaluation of alexithymia and depression in severe obese patients not affected by eating disorders. Eating and Weight DisordersStudies on Anorexia, Bulimia and Obesity, 16(1), 24-29. doi: 10.1007/BF03327517 
Darby, A., Hay, P., Mond, J., Quirk, F., Buttner, P., \& Kennedy, L. (2009). The rising prevalence of comorbid obesity and eating disorder behaviors from 1995 to 2005. International Journal of Eating Disorders, 42(2), 104-108. doi:10.1002/eat.20601.

Davin, S. A., \& Taylor, N. M. (2009). Comprehensive review of obesity and psychological considerations for treatment. Psychology, health \& medicine, 14(6), 716-725.

Dymek, M.P., Le Grange, D., \& Neven, K., (2001), Quality of life and psychosocial adjustment in patients after Roux-en-y gastric bypass: a brief report. Obesity Surgery, Vol. 11, pp. 32-39.

Eizaguirre, A. E., de Cabezon, A. O. S., de Alda, I. O., Olariaga, L. J., \&Juaniz, M. (2004).

Alexithymia and its relationships with anxiety and depression in eating disorders. Personality and Individual Differences, 36(2), 321-331. doi: 10.1016/S0191-8869(03)00099-0

Elfhag, K., \&Lundh, L. G. (2007). TAS-20 alexithymia in obesity, and its links to personality. Scandinavian Journal of Psychology, 48(5), 391-398. doi:10.1111/j.1467-9450.2007.00583.x

Elfhag K., \&Rössner S. (2005). Who succeeds in maintaining weight loss? A conceptual review of factors associated with weight loss maintenance and weight regain. Obesity reviews. 6 (1), 67-85. doi: 10.1111/j.1467-789X.2005.00170.x

Ernst, J., Böker, H., Hättenschwiler, J., Schüpbach, D., Northoff, G., Seifritz, E., \& Grimm, S. (2014). The association of interoceptive awareness and alexithymia with neurotransmitter concentrations in insula and anterior cingulate. Social cognitive and affective neuroscience, 9, 857-863. doi: $10.1093 / \mathrm{scan} / \mathrm{nst} 058$ 
Fernandes, J., Ferreira-Santos, F., Miller, K., \& Torres, S. (2017). Emotional processing in obesity: a systematic review and exploratory meta-analysis. ObesityReviews, 19(1), 111-120. doi: $10.1111 /$ obr.12607

Franzoni, E., Gualandi, S., Caretti, V., Schimmenti, A., Di Pietro, E., Pellegrini, G., ... \&Pellicciari, A. (2013). The relationship between alexithymia, shame, trauma, and body image disorders: investigation over a large clinical sample. Neuropsychiatric Disease and Treatment, 9, 185.

doi: $10.2147 /$ NDT.S34822

Garawi, F., Devries, K., Thorogood, N., \&Uauy, R. (2014). Global differences between women and men in the prevalence of obesity: is there an association with gender inequality? European journal of clinical nutrition, 68, 1101-1106. doi: 10.1038/ejen.2014.86

General Assembly of the World Medical Association. (2014). World Medical Association Declaration of Helsinki: ethical principles for medical research involving human subjects. The Journal of the American College of Dentists, 81(3), 14.

Gianini, L. M., White, M. A., \&Masheb, R. M. (2013). Eating pathology, emotion regulation, and emotional overeating in obese adults with binge eating disorder. Eating behaviors, 14(3), 309-313. doi: $10.1016 /$ j.eatbeh.2013.05.008

Goode, R. W., Ye, L., Sereika, S. M., Zheng, Y., Mattos, M., Acharya, S. D., ... Chasens, E. (2016). Socio-demographic, anthropometric, and psychosocial predictors of attrition across behavioral weightloss trials. Eating behaviors, 20, 27-33. doi:10.1016/j.eatbeh.2015.11.009

Gormally, J., Black, S., Daston, S., \&Rardin, D. (1982). The assessment of binge eating severity among obese persons. Addictive behaviors, 7(1), 47-55. doi:10.1016/0306-4603(82)90024-7 
Greeno, C.G., Marcus, M.D., \& Wing, R.R. (1995). Diagnosis of binge eating disorder: Discrepancies between a questionnaire and clinical interview. International Journal of Eating Disorders, 17(2), 153160. doi:10.1002/1098-108X(199503)17:2<153::AID-EAT2260170208>3.0.CO;2-V

Grucza, R. A., Przybeck, T. R., \&Cloninger, C. R. (2007). Prevalence and correlates of binge eating disorder in a community sample. Comprehensive psychiatry, 48(2), 124-131. doi: $10.1016 /$ j.comppsych.2006.08.002

Harrison, A., Sullivan, S., Tchanturia, K., \& Treasure, J. (2010). Emotional functioning in eating disorders: attentional bias, emotion recognition and emotion regulation. Psychological Medicine, 40(11), 1887-1897. doi: 10.1017/S0033291710000036

Heatherton, T.F., \&Baumeister, R.F. (1991). Binge eating as escape from self-awareness. Psychological Bulletin, 110, 86-108.

Herbert, B. M., Herbert, C., \&Pollatos, O. (2011). On the relationship between interoceptive awareness and alexithymia: is interoceptive awareness related to emotional awareness? Journal of personality, 79(5), 1149-1175. doi:10.1111/j.1467-6494.2011.00717.x

Hilbert, A., \&Tuschen-Caffier, B. (2007). Maintenance of binge eating through negative mood: A naturalistic comparison of binge eating disorder and bulimia nervosa. International Journal of Eating Disorders, 40(6), 521-530. doi: https://doi.org/10.1002/eat.20401

Honkalampi, K., De Berardis, D., Vellante,F., \&Viinamäki, H. (2018). "Relations between Alexithymia and Depressive and Anxiety Disorders and Personality”, in Luminet, O., Bagby, R. M., \& Taylor, G. J. (Eds.). Alexithymia: Advances in Research, Theory, and Clinical Practice. Cambridge, UK: Cambridge University Press. 
Honkalampi, K., Hintikka, J., Laukkanen, E., Lehtonen, J., \&Viinama ki, H. (2001). Alexithymia and depression: A prospective study of patients with major depressive disorder, Journal of Psychosomatics, 42, 229-234. doi: 10.1176/appi.psy.42.3.229

Honkalampi, K., Ruusunen, A., Viinamäki, H., Koivumaa-Honkanen, H., Valkonen-Korhonen, M., \&Lehto, S. M. (2017). Dietary patterns are associated with the prevalence of alexithymia. Scandinavian journal of psychology, 58(4), 318-323. doi:10.1111/sjop.12370

Hruby, A., \& Hu, F. B. (2015). The epidemiology of obesity: a big picture. Pharmacoeconomics, 33(7), 673-689. doi: $10.1007 / \mathrm{s} 40273-014-0243-\mathrm{X}$

Hudson, J., Hiripi, E., Pope, H., \& Kessler, R. (2007). The prevalence and correlates of eating disorders in the National Comorbidity Survey Replication. Biological Psychiatry, 61, 348e358. doi: $\underline{10.1016 / j . b i o p s y c h .2006 .03 .040}$

Jenkinson, P. M., Taylor, L., \& Laws, K. R. (2018). Self-reported interoceptive deficits in eating disorders: A meta-analysis of studies using the eating disorder inventory. Journal of psychosomatic research, 110, 38-45. doi:10.1016/j.jpsychores.2018.04.005

Kano, M., Hamaguchi, T., Itoh, M., Yanai, K., \&Fukudo, S. (2007). Correlation between alexithymia and hypersensitivity to visceral stimulation in human. Pain 132, 252-263. doi:10.1016/j.pain.2007.01.032

Kanter, R., \& Caballero, B. (2012). Global Gender Disparities in Obesity: A Review. Advances in nutrition, 3, 491-498.doi: 10.3945/an.112.002063 
Karvonen, J.T., Veijola, J., Kokkonen, P., Läksy, K., Miettunen, J., \&Joukamaa, M. (2005)

Somatization and alexithymia in young adult Finnish population. General hospital psychiatry, 27, 244249. doi:10.1016/j.genhosppsych.2005.04.005

Kirsten, P. M., \&Ridout, N. (2018). “Alexithymia and Maladaptive Regulatory Behaviors in Substance Use Disorders and Eating Disorders”, in Luminet, O., Bagby, R. M., \& Taylor, G. J. (Eds.). Alexithymia: Advances in Research, Theory, and Clinical Practice. Cambridge, UK: Cambridge University Press.

Larsen, J. K., van Strien, T., Eisinga, R., \& Engels, R. C. (2006). Gender differences in the association between alexithymia and emotional eating in obese individuals. Journal of Psychosomatic Research, 60(3), 237-243. doi: https://doi.org/10.1016/j.jpsychores.2005.07.006

Leweke, F., Leichsenring, F., Kruse, J., \& Hermes, S. (2012) Is alexithymia associated with specific mental disorders? Psychopathology, 45, 22-28. doi:10.1159/000325170

Li, S., Zhang, B., Guo, Y., \& Zhang, J. (2015). The association between alexithymia as assessed by the 20-item Toronto Alexithymia Scale and depression: a meta-analysis. Psychiatry research, 227(1), 1-9. doi:10.1016/j.psychres.2015.02.006

Loas, G., Corcos, M., Stephan, P., Pellet, J., Bizouard, P., Venisse, J. L., ... Jeammet, P. (2001). Factorial structure of the 20-item Toronto Alexithymia Scale: confirmatory factorial analyses in nonclinical and clinical samples. Journal of psychosomatic research, 50(5), 255-261. doi:10.1016/S0022-3999(01)00197-0

Luminet, O., Bagby, R. M., \& Taylor, G. J. (Eds.). (2018). Alexithymia: Advances in Research, Theory, and Clinical Practice. Cambridge, UK: Cambridge University Press. 
Makino, M., Tsuboi, K., \&Dennerstein, L. (2004). Prevalence of eating disorders: A comparison of Western and non-Western countries. Medscape General Medicine, 6(3), 49.

Marcus, M. D., Wing, R. R., \& Hopkins, J. (1988). Obese binge eaters: affect, cognitions, and response to behavioural weight control. Journal of consulting and clinical psychology. 56, 433-439.

Mattila, A. K., Kronholm, E., Jula, A., Salminen, J. K., Koivisto, A. M., Mielonen, R. L., \&Joukamaa, M. (2008). Alexithymia and somatization in general population. Psychosomatic Medicine, 70(6), 716722. doi:10.1097/PSY.0b013e31816ffc39

Melin, E. O., Svensson, R., Thunander, M., Hillman, M., Thulesius, H. O., \& Landin-Olsson, M. (2017). Gender, alexithymia and physical inactivity associated with abdominal obesity in type 1 diabetes mellitus: a cross sectional study at a secondary care hospital diabetes clinic. BMC obesity, 4(1), 21. doi: $10.1186 / \mathrm{s} 40608-017-0157-1$

Mozaffarian, D., Hao, T., Rimm, E. B., Willett, W. C., \& Hu, F. B. (2011). Changes in diet and lifestyle and long-term weight gain in women and men. New England Journal of Medicine, 364(25), 2392-2404. doi:10.1056/NEJMoa1014296.

Nakao, M., Barsky, A. J., Kumano, H., \&Kuboki, T. (2002). Relationship between somatosensory amplification and alexithymia in a Japanese psychosomatic clinic. Psychosomatics 43, 55-60. doi:10.1176/appi.psy.43.1.55

NCD Risk Factor Collaboration. (2016). Trends in adult body-mass index in 200 countries from 1975 to 2014: a pooled analysis of 1698 population-based measurement studies with $19 \cdot 2$ million participants. The Lancet, 387(10026), 1377-1396. doi:10.1016/S0140-6736(16)30054-X 
Nicholls, W., Devonport, T. J., \& Blake, M. (2016). The association between emotions and eating behaviour in an obese population with binge eating disorder. Obesity reviews, 17(1), 30-42. doi: $10.1111 /$ obr.12329

Norton, S., Cosco, T., Doyle, F., Done, J., \& Sacker, A. (2013). The Hospital Anxiety and Depression Scale: A meta- confirmatory factor analysis. Journal of psychosomatic research, 74, 74-81. doi:10.1016/j.jpsychores.2012.10.010

Nowakowski, M. E., McFarlane, T., \& Cassin, S. (2013). Alexithymia and eating disorders: A critical review of the literature. Journal of Eating Disorders, 1, 21. 10.1186/2050-2974-1-21. doi: $10.1186 / 2050-2974-1-21$

Ogrodniczuk, J.S., Kealy, D., Hadjipavlou, G.A., \& Cameron, K. (2018). Therapeutic Issues. In Alexithymia. Advances in Research, Theory, and Clinical Practice, ed. O. Luminet, R.M. Bagby\& G.J. Taylor. Cambridge, UK: Cambridge University Press, pp. 190-206.

Ouwens, M. A., van Strien, T., \& van Leeuwe, J. F. (2009). Possible pathways between depression, emotional and external eating. A structural equation model. Appetite, 53(2), 245-248.

Pagoto, S., Bodenlos, J. S., Kantor, L., Gitkind, M., Curtin, C., \& Ma, Y. (2007). Association of major depression and binge eating disorder with weight loss in a clinical setting. Obesity, 15(11), 2557-2559. doi:10.1038/oby.2007.307

Parker, J. D., Taylor, G. J., \&Bagby, R. M. (2003). The 20-Item Toronto Alexithymia Scale: III. Reliability and factorial validity in a community population. Journal of psychosomatic research, 55(3), 269-275. doi: $10.1016 / \mathrm{S} 0022-3999(02) 00578-0$ 
Pike, K. M., \&Dunne, P. E. (2015). The rise of eating disorders in Asia: A review. Journal of Eating Disorders, 3(33), doi:10.1186/s40337-015-0070-2

Pinaquy, S., Chabrol, H., Simon, C., Louvet, J. P., \&Barbe, P. (2003). Emotional eating, alexithymia, and binge-eating disorder in obese women. Obesity, 11(2), 195-201. doi:10.1038/oby.2003.31

Pinna, F., Lai, L., Pirarba, S., Orru, W., Velluzzi, F., Loviselli, A., \&Carpiniello, B. (2011). Obesity, alexithymia and psychopathology: a case-control study. Eating and Weight Disorders-Studies on Anorexia, Bulimia and Obesity, 16(3), e164-e170. doi:10.3275/7509

Pi-Sunyer, X. (2009). The medical risks of obesity. Postgraduate medicine, 121(6), 21-33. doi:10.3810/pgm.2009.11.2074.

Porcelli, P., De Carne, M., \& Leandro, G. (2014). Alexithymia and gastrointestinal-specific anxiety in moderate to severe irritable bowel syndrome. Comprehensive psychiatry, 55(7), 1647-1653. doi:10.1016/j.comppsych.2014.05.022

Saarijarvi, S., Salminen, J.K., \&Toikka, T.B. (2001). Alexithymia and depression: a 1-year follow-up study in outpatients with major depression. Journal of Psychosomatich Research, 51, 729-733. doi:10.1016/S0022-3999(01)00257-4

Sawamoto, R., Nozaki, T., Furukawa, T., Tanahashi, T., Morita, C., Hata, T., ... Sudo, N. (2016). Predictors of dropout by female obese patients treated with a group cognitive behavioral therapy to promote weight loss. Obesityfacts, 9(1), 29-38. doi: $\underline{10.1159 / 000442761}$

Scarpazza, C., Làdavas, E., \& di Pellegrino, G. (2015). Dissociation between emotional remapping of fear and disgust in alexithymia. PloS one, 10(10), e0140229. doi:10.1371/journal.pone.0140229 
Schumacker, R. E., \&Lomax, R. G. (1996). A Beginner's Guide to Structural Equation Modeling. Mahwah, New Jersey

Simmons, W. K., \&DeVille, D. C. (2017). Interoceptive contributions to healthy eating and obesity. Current opinion in psychology, 17, 106-112. doi:10.1016/j.copsyc.2017.07.001

Speranza, M., Corcos, M., Loas, G., Stephan, P., Guilbaud, O., Perez-Diaz, F. .. Jeammet, P. (2005). Depressive personality dimensions and alexithymia in eating disorders. PsychiatryResearch, 135(2), 153-163.

Speranza, M., Loas, G., Wallier, J., \&Corcos, M. (2007). Predictive value of alexithymia in patients with eating disorders: A 3-year prospective study. Journal of psychosomatic research, 63(4), 365-371. doi:10.1016/j.jpsychores.2007.03.008

Stice, E., Agras, W. S., Telch, C. F., Halmi, K. A., Mitchell, J. E., \& Wilson, T. (2001). Subtyping binge eating-disordered women along dieting and negative affect dimensions. International Journal of Eating Disorders, 30(1), 11-27.

Svaldi, J., Griepenstroh, J., Tuschen-Caffier, B., \&Ehring, T. (2012). Emotion regulation deficits in eating disorders: a marker of eating pathology or general psychopathology? Psychiatry Research, 197(1), 103-111.doi: 10.1016/j.psychres.2011.11.009

Swift, L., Stephenson, R., \& Royce, J. (2006). The 20-item Toronto Alexithymia Scale: Validation of factor solutions using confirmatory factor analysis on physiotherapy out-patients. Psychology and Psychotherapy: Theory, Research and Practice, 79(1), 83-88. doi:10.1348/147608305X42875 
Taylor, G. J., \&Bagby, R. M. (2013). Psychoanalysis and empirical research: The example of alexithymia. Journal of the american psychoanalytic association, 61(1), 99-133. doi: $10.1177 / 0003065112474066$

Taylor, G.J., Bagby, R.M., \& Parker, J.D.A. (1997). Disorders of affect regulation. Alexithymia in medical and psychiatric illness. Cambridge, UK: Cambridge University Press.

Taylor, G. J., Bagby, R. M., \& Parker, J. D. (2003). The 20-Item Toronto Alexithymia Scale: IV. Reliability and factorial validity in different languages and cultures. Journal of Psychosomatic Research, 55, 277-283. doi:10.1016/S0022-3999(02)00601-3

Torres, S., Guerra, M. P., Lencastre, L., Miller, K., Vieira, F. M., Roma-Torres, A., ... Costa, P. (2015). Alexithymia in anorexia nervosa: the mediating role of depression. Psychiatry research, 225(1-2), 99107. doi:10.1016/j.psychres.2014.10.023

van der Velde, J., Swart, M., van Rijn, S., van der Meer, L., Wunderink, L., Wiersma, D., ... Aleman, A. (2015). Cognitive alexithymia is associated with the degree of risk for psychosis. PloS one, 10(6), e0124803. doi:10.1371/journal.pone.0124803

Westwood, H., Kerr-Gaffney, J., Stahl, D., \&Tchanturia, K. (2017). Alexithymia in eating disorders: Systematic review and meta-analyses of studies using the Toronto Alexithymia Scale. Journal of Psychosomatic Research. doi:10.1016/j.jpsychores.2017.06.007

Wheeler, K., Greiner, P., \&Boulton, M. (2005). Exploring Alexithymia, depression, and binge eating in self-reported eating disorders in women. Perspectives in Psychiatric Care, 41(3), 114-123. doi:10.1111/j.1744-6163.2005.00022.X 
World Health Organization. (2000). Obesity: preventing and managing the global epidemic (No. 894). World Health Organization.

World Health Organization. (2009). Global health risks: mortality and burden of disease attributable to selected major risks. World Health Organization.

Zigmond A.S., \&SnaithR.P. (1983). The Hospital Anxiety and Depression Scale. Acta PsychiatricaScandinavica. 67(6); 361 - 370. doi:10.1111/j.1600-0447.1983.tb09716.x 
Table 1. Socio-demographic and clinical characteristics of the study sample $(\mathrm{N}=361)$

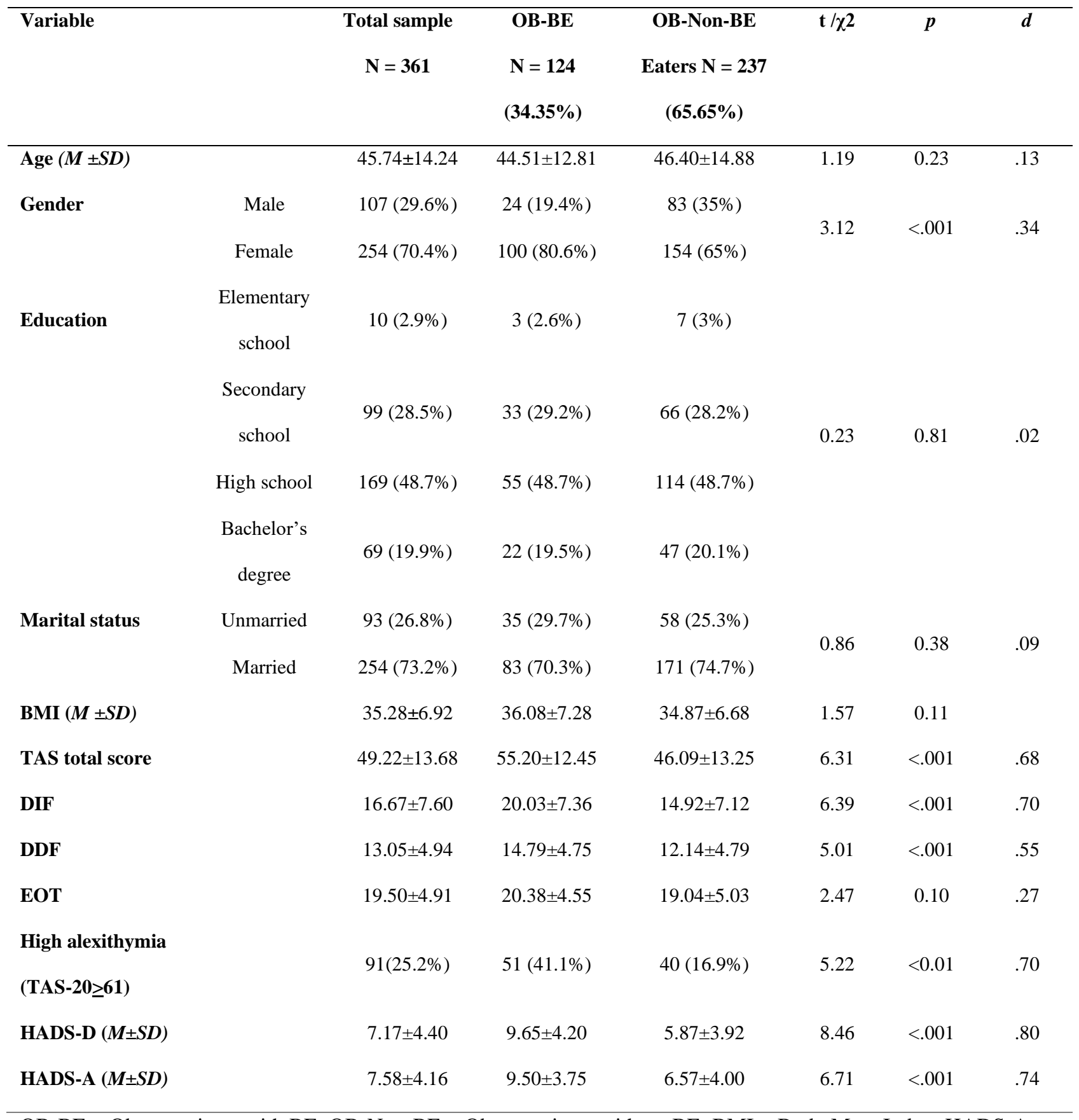

$\mathrm{OB}-\mathrm{BE}=$ Obese patients with BE; OB-Non-BE = Obese patients without BE; BMI = Body Mass Index; HADS-A = Hospital Anxiety and Depression Scale-Anxiety subscale; HADS-D = Hospital Anxiety and Depression Scale-Depression subscale; TAS-20 = 20-item Toronto Alexithymia Scale. 
Table 2. Predictors of BE (binary regression)

\begin{tabular}{|c|c|c|c|c|}
\hline & $\boldsymbol{\beta}$ & OR (95\% C.I.) & p_value & $\mathbf{R}^{2}$ \\
\hline Model 1 & & & & 0.02 \\
\hline Age & -0.01 & $0.99(0.97-1.01)$ & 0.41 & \\
\hline Gender (female) & 0.76 & $2.15(1.25-3.71)$ & $<0.01$ & \\
\hline Education & -0.07 & $0.92(0.69-1.23)$ & 0.59 & \\
\hline Marital status & -0.26 & $0.76(0.44-1.31)$ & 0.33 & \\
\hline Model 2 & & & & 0.03 \\
\hline$+\mathrm{BMI}$ & 0.02 & $1.02(0.99-1.05)$ & 0.17 & \\
\hline Model 3 & & & & 0.17 \\
\hline +HADS-A & 0.09 & $1.10(1.02-1.18)$ & $<0.01$ & \\
\hline +HADS-D & 0.18 & $1.20(1.11-1.29)$ & $<0.001$ & \\
\hline Model 4 & & & & 0.19 \\
\hline+ TAS-20 & 0.31 & $1.03(1.01-1.05)$ & $<0.001$ & \\
\hline
\end{tabular}

BMI = Body Mass Index; HADS-A = Hospital Anxiety and Depression Scale-Anxiety subscale; HADS-D = Hospital Anxiety and Depression Scale-Depression subscale; TAS-20 = 20-item Toronto Alexithymia Scale. 
Table 3. Effects of exogenous constructs in model

\begin{tabular}{|c|c|c|c|c|c|c|c|}
\hline $\begin{array}{l}\text { Endogenous } \\
\text { Variables }\end{array}$ & $\begin{array}{l}\text { Exogenous } \\
\text { variables }\end{array}$ & $\beta$ & $\mathrm{z}$ & $\mathrm{R}^{2}$ & Direct effects & Indirect effects & Total effects \\
\hline \multirow[t]{3}{*}{ HADS-A } & DIF & .45 & - & .23 & $.45 * * *$ & & \\
\hline & DDF & .17 & 1.86 & & $.17 *$ & & \\
\hline & EOT & -.03 & -0.35 & & -.03 & & \\
\hline \multirow[t]{3}{*}{ HADS-D } & DIF & .34 & 3.94 & .17 & $.34 * * *$ & & \\
\hline & DDF & .22 & 2.41 & & $.22 *$ & & \\
\hline & EOT & .07 & - & & .07 & & \\
\hline \multirow[t]{5}{*}{ BES } & DIF & .20 & 4.02 & .25 & $.20^{*}$ & $.19 * * *$ & $.39 * *$ \\
\hline & DDF & .02 & 1.36 & & .02 & $.09 * *$ & .11 \\
\hline & EOT & -.02 & -0.29 & & -.02 & .06 & -.02 \\
\hline & HADS-A & .27 & 3.67 & & $.27 * * *$ & & $.27 * * *$ \\
\hline & HADS-D & .19 & 2.94 & & $.19 * *$ & & $.19 * *$ \\
\hline
\end{tabular}

HADS-A = Hospital Anxiety and Depression Scale-Anxiety subscale; HADS-D = Hospital Anxiety and Depression ScaleDepression subscale; DIF=difficulty identifying feelings; DDF=difficulty describing feelings; EOT= externally orientated thinking; BES=Binge Eating Scale. Note: ${ }^{*} p<.05 . * * p<.01 . * * * p<.001$ 
Figure 1. Structural equation modeling among DIF, DDF, EOT, depression and anxiety symptoms and BE. 